Article

\title{
Novel Gold Dendritic Nanoforests Combined with Titanium Nitride for Visible-Light-Enhanced Chemical Degradation
}

\author{
Ming-Hua Shiao ${ }^{1}$, Chun-Ting Lin ${ }^{1}$, Jian-Jia Zeng ${ }^{2}$ and Yung-Sheng Lin ${ }^{2, *}$ \\ 1 Instrument Technology Research Center, National Applied Research Laboratories, Hsinchu 300, Taiwan; \\ mhshiao@narlabs.org.tw (M.-H.S.); chunting.pineapple.lin@gmail.com (C.-T.L.) \\ 2 Department of Chemical Engineering, National United University, Miaoli 360, Taiwan; 182178253@gmail.com \\ * Correspondence: linys@nuu.edu.tw; Tel.: +886-37-382-199
}

Received: 14 February 2018; Accepted: 24 April 2018; Published: 26 April 2018

\begin{abstract}
In this study, gold dendritic nanoforests (Au DNFs)-titanium nitride (TiN) composite was firstly proposed for visible-light photodegradation of pollutants. A high-power impulse magnetron sputtering system was used to coat TiN films on silicon wafers, and a fluoride-assisted galvanic replacement reaction was applied to deposit Au DNFs on TiN/Si substrates. Scanning electron microscope images and X-ray diffraction patterns of TiN/Si, Au DNFs/Si, and Au DNFs/TiN/Si samples verified that this synthesis process was accurately controlled. The average reflectance of $\mathrm{Au}$ DNFs/Si and Au DNFs/TiN/Si considerably declined to approximately 10\%, because the broadband localized surface plasmon resonances of Au DNFs cause broadband absorbance and low reflectance. In photocatalytic performance, $90.66 \pm 1.41 \%$ 4-nitrophenol was successfully degraded in $180 \mathrm{~min}$ by $\mathrm{Au} \mathrm{DNFs} / \mathrm{TiN} / \mathrm{Si}$ under visible-light irradiation. Therefore, Au DNFs/TiN/Si has the chance to be a visible-light photocatalyst for photodegradation of pollutants.
\end{abstract}

Keywords: photocatalyst; degradation; gold; titanium nitride

\section{Introduction}

Titanium dioxide $\left(\mathrm{TiO}_{2}\right)$ is the most widely used photocatalyst in the photodegradation of pollutants because of its strong oxidizing abilities, chemical stability, nontoxicity, and low cost [1]. Although $\mathrm{TiO}_{2}$ is widely used as a benchmark for other photocatalysts, $\mathrm{TiO}_{2}$ only absorbs the ultraviolet (UV) region of the solar spectrum; this limited absorption is an obstacle to the wide application of $\mathrm{TiO}_{2}$ for the photodegradation of pollutants [2]. Therefore, various photosensitized degradation processes have attracted considerable attention because they can harvest maximal solar energy by utilizing visible light to degrade pollutants [2]. Introducing nanosized metal materials [3-7] or a doping $\mathrm{N}$ element [8] to reduce the band gap energy can extend the activating spectrum of $\mathrm{TiO}_{2}$ from $\mathrm{UV}$ to the visible spectrum and enhance performance.

Titanium nitride (TiN) is an extremely hard ceramic material with well-known thermal, chemical, and mechanical stability properties. TiN is applied as a thin film coating to harden and protect cutting and sliding surfaces of industrial machine tools. TiN has particular optical and metallic properties and possesses potentially resonant plasmon characteristics in the visible spectrum [9-11]. A study demonstrated that TiN can exhibit electromagnetic field enhancements comparable to those of gold $\mathrm{Au}$ ) nanostructures [12]. TiN exhibited higher electrical conductivity and optical absorption in long wavelength range than Ti [13]. Studies of depositing silver [14-16] or copper [17] on TiN substrates for applications have been reported. However, few studies have been published regarding gold nanostructure/TiN composite materials for applications. 
Gold nanoparticles and nanostructures exhibit characteristic optical properties because of localized surface plasmon resonance (LSPR), which are dependent on the sizes and shapes of nanomaterials [18]. Therefore, gold nanoparticles and nanostructures with different sizes have different characteristic LSPR wavelengths. Gold dendritic nanoforests (Au DNFs) have attracted considerable attention due to their noteworthy specific surface area and strong LSPR enhancement for wide wavelengths [19]. However, the synergetic effects of Au DNFs combined with TiN on photodegradation have not been reported. In this study, Au DNF/TiN/Si composite samples were applied to photocatalytically degrade organic dyes under visible-light illumination.

\section{Materials and Methods}

\subsection{Sample Preparation}

TiN films were deposited on silicon wafers by physical vapor deposition with a high-power impulse magnetron sputtering system (HIPIMS) [20]. In brief, a 4-inch-diameter titanium target was mounted on one cathode and a pulse generator with a frequency of $20 \mathrm{kHz}$ was applied. The pressure of the deposition chamber was pumped down to less than $8 \times 10^{-6}$ Torr by using a cryopump. Before the deposition of the TiN layer, a Ti layer was deposited on the silicon wafer to connect Si and TiN. The parameters used in the chamber to prepare Ti and TiN layers are listed in Table 1. In this study, the thicknesses of $\mathrm{Ti}$ and $\mathrm{TiN}$ were 50 and $300 \mathrm{~nm}$, respectively.

Table 1. High-power impulse magnetron sputtering system (HIPIMS) parameters for deposition of Ti and TiN layers.

\begin{tabular}{ccccc}
\hline Layer & DC Power $(\mathbf{W})$ & Impulse Period $(\boldsymbol{\mu s})$ & Ar Flow Rate $(\mathbf{s c c m})$ & $\mathbf{N}_{\mathbf{2}}$ Flow Rate $(\mathbf{s c c m})$ \\
\hline $\mathrm{Ti}$ & 250 & 90 & 20 & - \\
$\mathrm{TiN}$ & 300 & 1000 & 30 & 1.5 \\
\hline
\end{tabular}

The synthesis of Au DNFs basically follows a fluoride-assisted galvanic replacement reaction (FAGRR) [19] that is widely used to deposit metal nanoparticles on Si substrate. The reactions are generally agreed as follow:

$$
\begin{aligned}
& \text { Anode: } \mathrm{Si}+6 \mathrm{~F}^{-} \rightarrow \mathrm{SiF}_{6}{ }^{2-}+4 \mathrm{e}^{-} \\
& \text {Cathode: } \mathrm{AuCl}_{4}{ }^{-}+3 \mathrm{e}^{-} \rightarrow \mathrm{Au}+4 \mathrm{Cl}^{-}
\end{aligned}
$$

In the case of TiN substrate, the anodic reaction proceeds as follow [21]:

$$
\text { Anode: } \mathrm{TiN}+3 \mathrm{HF}_{2}^{-} \rightarrow \mathrm{TiF}_{6}{ }^{2-}+\mathrm{NH}_{3}+\mathrm{e}^{-}
$$

An $n$-type silicon wafer $(2 \times 2 \mathrm{~cm})$ was dipped in a mixture of $10 \mathrm{mM}$ chloroauric acid $\left(\mathrm{HAuCl}_{4}\right)$ and buffered oxide etchant solution containing $11.3 \% \mathrm{NH}_{4} \mathrm{~F}$ and $2.3 \% \mathrm{HF}$ for 3 min in a typical manner. Then, the sample was washed with deionized water, dried using an $\mathrm{N}_{2}$ spray, and incubated at $120{ }^{\circ} \mathrm{C}$ for 5 min to obtain an Au DNFs/Si sample. The Au DNFs/TiN/Si synthesis procedure was the same except that it used a TiN/Si substrate.

\subsection{Photodegradation}

The photodegradation experiment was conducted in a $250-\mathrm{mL}$ beaker. A solar simulator (class B; $\lambda>400 \mathrm{~nm}$; $150 \mathrm{~W}$; Sadhu Design Corporation, Hsinchu, Taiwan) was employed as the light source for the photodegradation experiment. The tested sample $(2 \mathrm{~cm} \times 2 \mathrm{~cm})$ was immersed in $10 \mathrm{~mL}$ 4-nitrophenol solution containing $2.5 \times 10^{-5} \mathrm{M}$ 4-nitrophenol and $0.125 \mathrm{M} \mathrm{NaBH}_{4}$, and the illumination power density was controlled at $70 \mathrm{~mW} / \mathrm{cm}^{2}$. The concentration of 4-nitrophenol was examined according to an absorption calibration curve at its maximum absorption wavelength. 
The degradation process was monitored every $30 \mathrm{~min}$ for $3 \mathrm{~h}$. All of the experiments were conducted in the ambient conditions.

\section{Results and Discussion}

\subsection{Morphology and Elemental Analysis}

Figure 1 shows scanning electron microscope (SEM) images and the corresponding energy-dispersive X-ray spectroscopy (EDS) spectrum of Au nanostructures on a silicon wafer prepared by a FAGRR. Results indicated that Au DNFs contained multiple levels of branches with features measuring 30-50 nm (Figure 1a,b). The side view picture (Figure 1c) indicated that evenly distributed $\mathrm{Au}$ DNFs were highly porous and the average thickness of free-standing Au DNFs was approximately $800 \mathrm{~nm}$ on the Si wafer. In an element analysis, only Au and Si signals were found in the Au DNFs/Si sample (Figure 1d), and the results reflected the absence of other byproducts from the FAGRR [19].

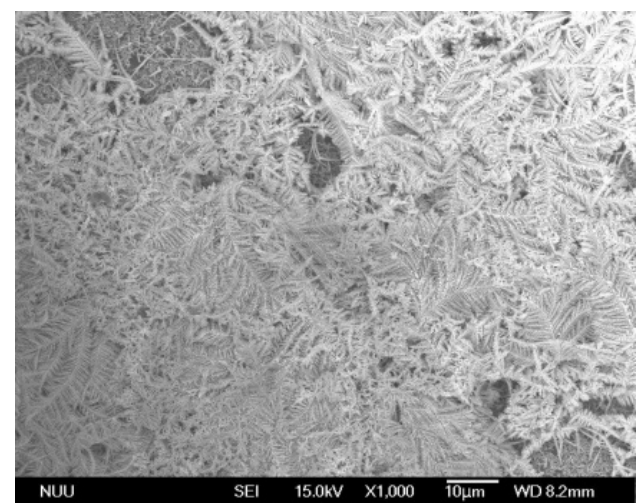

(a)

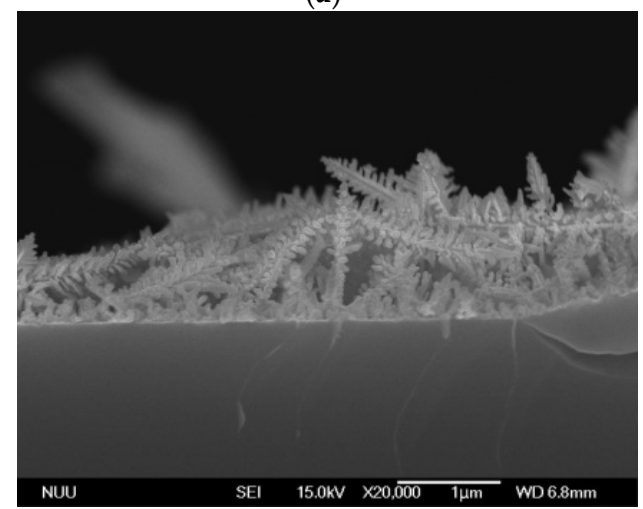

(c)

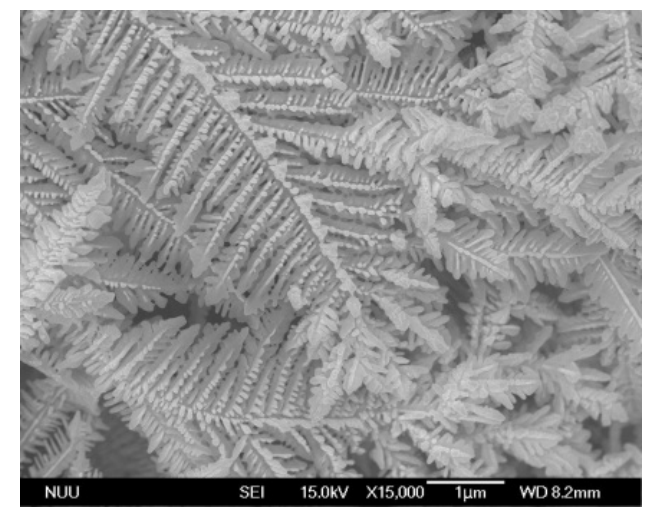

(b)

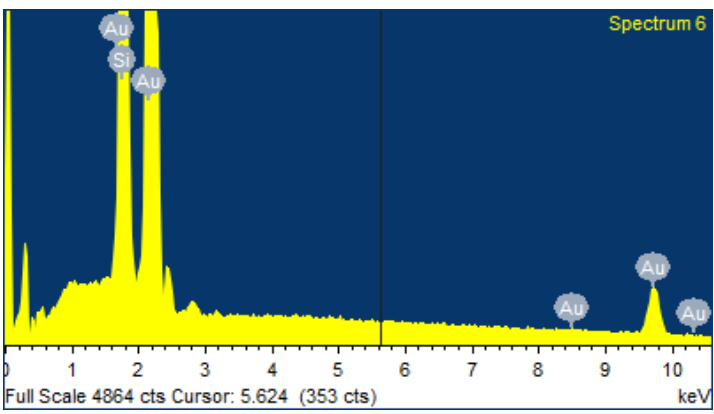

(d)

Figure 1. Scanning electron microscope (SEM) examination of Au DNFs/Si. (a,b) top view; (c) side view; (d) Energy-dispersive X-ray spectroscopy (EDS) spectrum.

Figure 2 presents SEM images and an EDS spectrum of Au nanostructures on a TiN/Si substrate fabricated by a FAGRR. Results indicated that leaf-like Au DNFs were loosely distributed on TiN/Si (Figure 2a,b). The Au DNFs/TiN/Si sample had a lower density of Au DNFs than did the Au DNFs/Si sample. The thickness of the Au DNFs was only approximately $650 \mathrm{~nm}$ (Figure 2c). Only Au, Ti, N, and Si signals were evident from the Au DNFs/TiN/Si sample (Figure 2d), corresponding to the result for the Au DNFs/Si sample. 


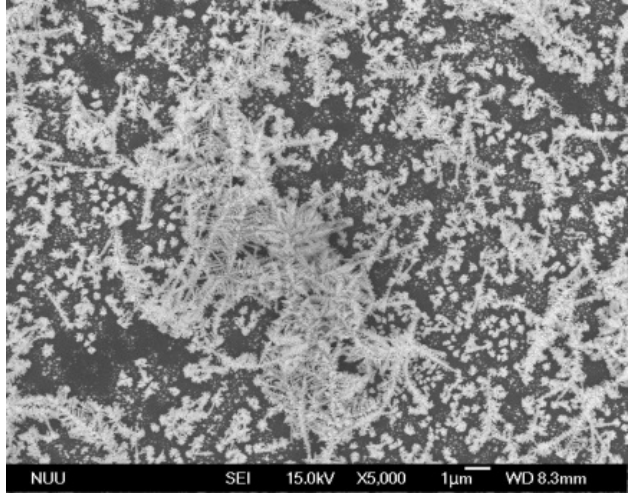

(a)

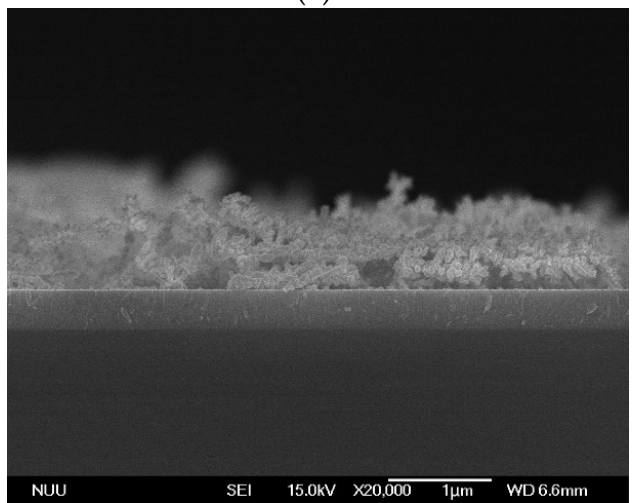

(c)

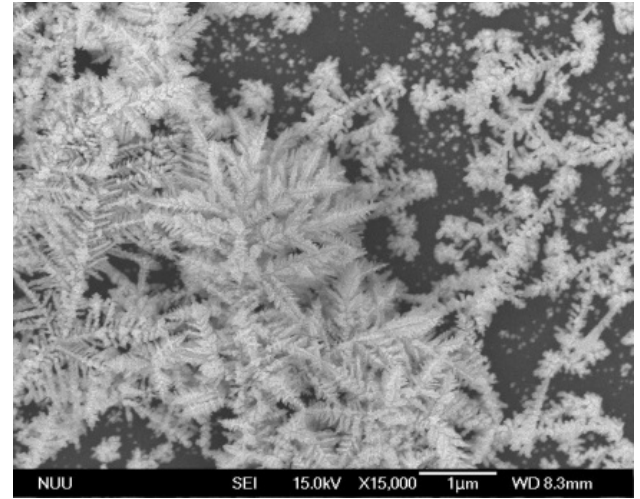

(b)

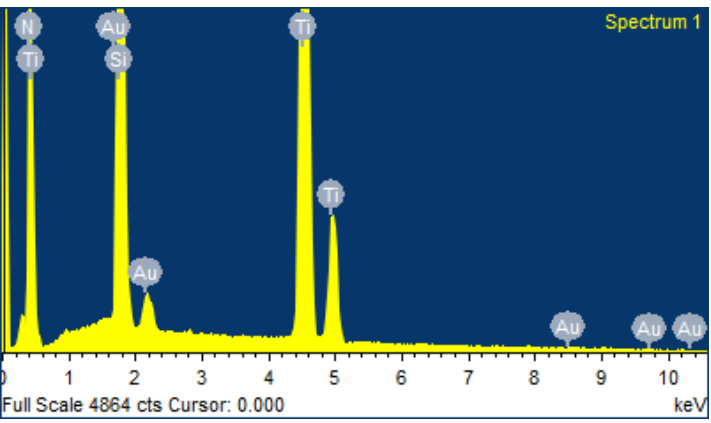

(d)

Figure 2. SEM examination of Au DNFs/TiN/Si. (a,b) top view; (c) side view; (d) EDS spectrum.

Figures 3 and 4 present transmission electron microscope (TEM) images and selected area electron diffraction (SAED) patterns of Au DNFs deposited on Si and TiN/Si substrates, respectively. To get clear TEM bright field images and diffraction information of Au DNFs, the deposition time of $\mathrm{Au}$ DNFs was controlled for $1 \mathrm{~min}$. The results indicate bright field images of Au DNFs deposited on both Si and TiN/Si substrates, and show the thickness of Au branches of less than 50 nm, which is suitable for TEM observations. It can be obviously observed that the trunks in the Au DNFs deposited on a single crystal of Si wafer substrate in Figure 3a are straighter and longer than those deposited on polycrystalline TiN substrate in Figure 4a. The SAED patterns reveal that the d-spacings of (111), (200), (220), and (311) planes corresponded to each of the diffraction rings in Figures $3 \mathrm{c}$ and $4 \mathrm{c}$.

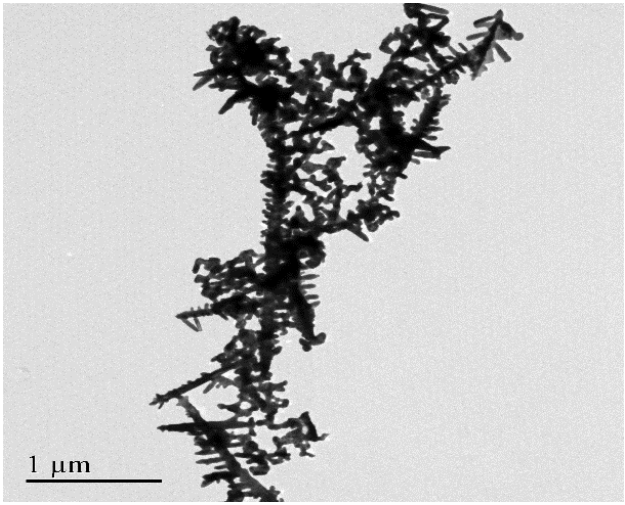

(a)

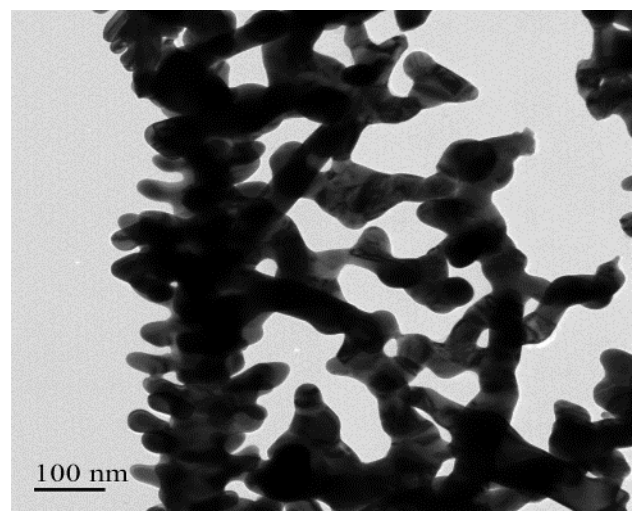

(b)

Figure 3. Cont. 


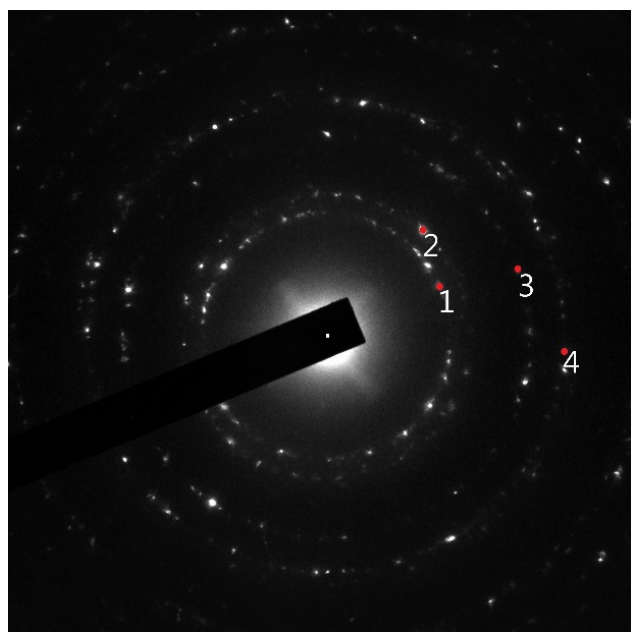

The d-spacings corresponded to SAED rings 1 to 4 .

\begin{tabular}{ccc}
\hline Ring & d-Spacing (nm) & $(\boldsymbol{h} \boldsymbol{k l})$ \\
\hline 1 & 0.2473 & $(111)$ \\
2 & 0.2121 & $(200)$ \\
3 & 0.1505 & $(220)$ \\
4 & 0.1273 & $(311)$ \\
\hline
\end{tabular}

(c)

Figure 3. Transmission electron microscope (TEM) examination of Au DNFs deposited on Si substrate. (a) Low-magnification; (b) High-magnification; (c) corresponding selected area electron diffraction (SAED) pattern of $(\mathbf{b})$.

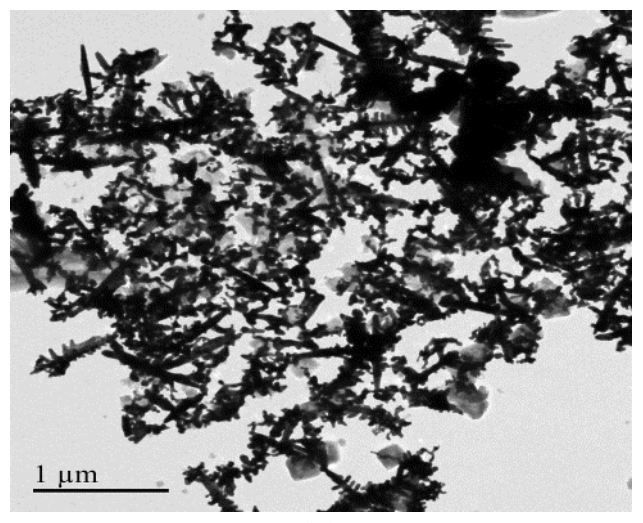

(a)

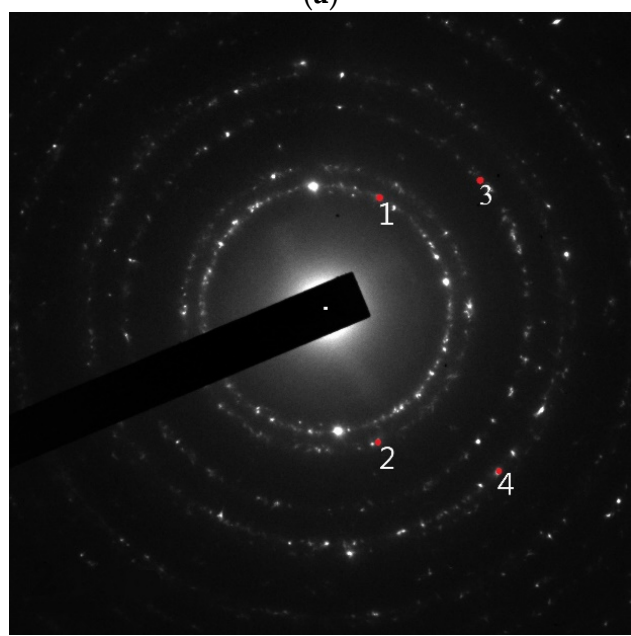

(c)

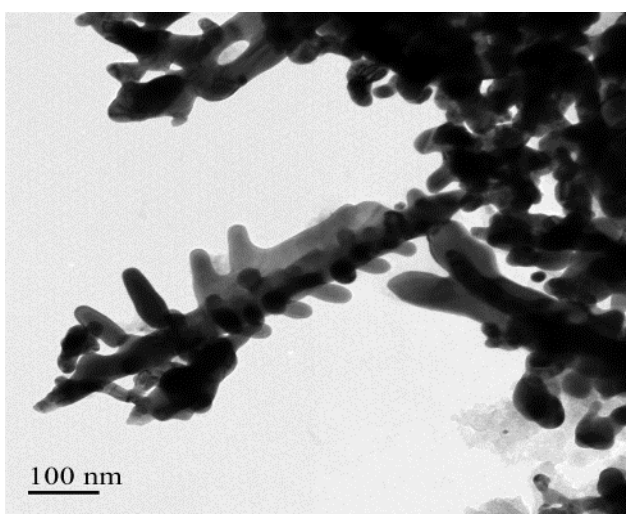

(b)

The d-spacings corresponded to SAED rings 1 to 4

\begin{tabular}{ccc}
\hline Ring & d-Spacing (nm) & $(\boldsymbol{h} \boldsymbol{k l})$ \\
\hline 1 & 0.2451 & $(111)$ \\
2 & 0.2107 & $(200)$ \\
3 & 0.1497 & $(220)$ \\
4 & 0.1272 & $(311)$ \\
\hline
\end{tabular}

Figure 4. TEM examination of Au DNFs deposited on TiN/Si substrate. (a) Low-magnification; (b) High-magnification; (c) corresponding SAED pattern of (b). 
Figure 5 further shows the TEM cross-section image of Au DNFs on the TiN/Si substrate, and the EDS line scan from Au DNFs cross the TiN layer to Si substrate. The microstructure of Au DNFs and columnar structure of TiN coating can be observed. The EDS line scan shows the measured intensities of $\mathrm{Au}, \mathrm{Ti}, \mathrm{N}$, and Si elements corresponded to the procedures we applied on the silicon wafer in sequence. The intensities of $\mathrm{C}, \mathrm{O}, \mathrm{Pt}$, and $\mathrm{Cu}$ were the background signals. Except background signals, there were almost only Ti signals at the interface of the TiN and Si substrate because a $50 \mathrm{~nm}$ Ti layer was deposited between the TiN layer and Si substrate (Table 1).
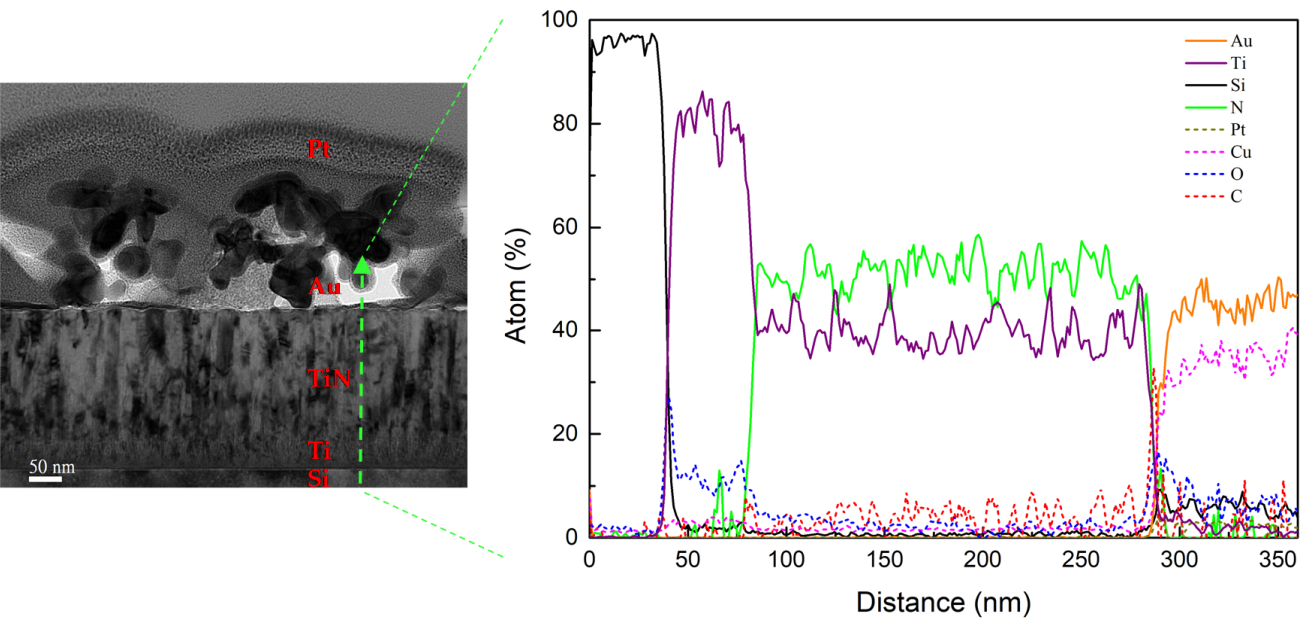

Figure 5. TEM elemental analysis of Au DNFs/TiN/Si sample.

Figure 6 shows the X-ray photoelectron spectroscopy (XPS) pattern of Au DNFs deposited on the TiN/Si substrate. The data was collected from a top plan of Au DNFs/TiN/Si sample. Results indicated that only $\mathrm{Au}, \mathrm{Ti}, \mathrm{N}, \mathrm{C}$, and $\mathrm{O}$ signals were evident. The atomic percentages were 34.2\%, $19.3 \%, 18.9 \%, 15.6 \%$, and $12.0 \%$ for C 1s, O 1s, Au 4f, N 1s, and Ti 2p, respectively. Among these elements, $\mathrm{C}$ and $\mathrm{O}$ were the background signals. Therefore, this result reflected the good control in preparing the Au DNFs/TiN/Si sample.

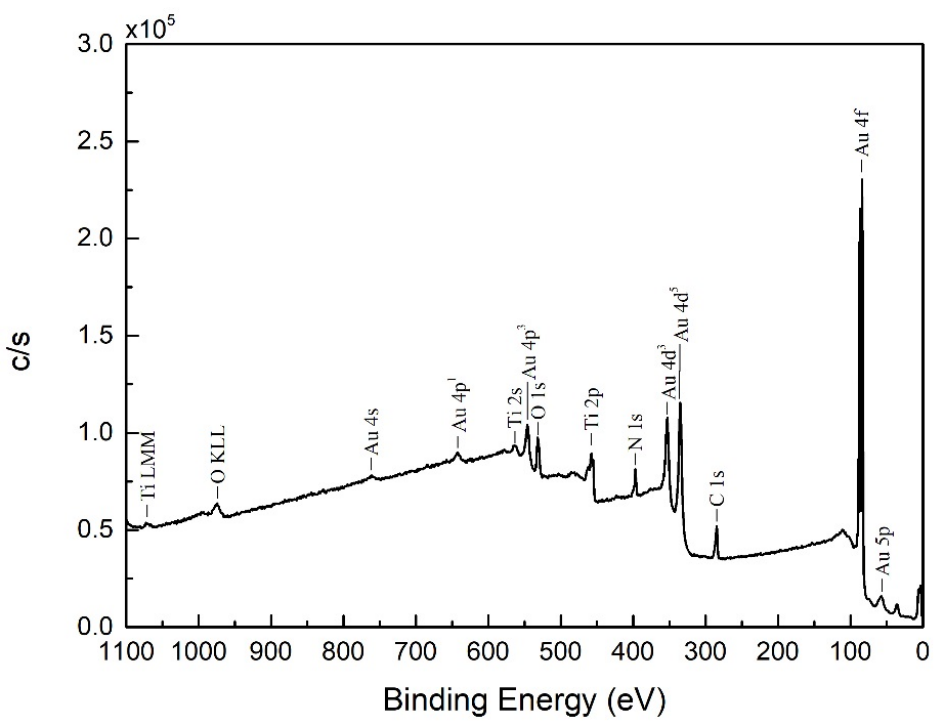

Figure 6. X-ray photoelectron spectroscopy (XPS) examination of Au DNFs deposited on TiN/Si substrate. 


\subsection{Crystalline}

Figure 7 shows the X-ray diffraction (XRD) pattern of Au samples deposited on a Si surface. Results indicated that $\mathrm{Au}$ has polycrystalline characteristics. Peaks of $\mathrm{Au}(111), \mathrm{Au}(200), \mathrm{Au}(220)$, and $\mathrm{Au}(311)$ were found in both $\mathrm{Au} \mathrm{DNFs} / \mathrm{Si}$ and $\mathrm{Au} \mathrm{DNFs} / \mathrm{TiN} / \mathrm{Si}$, which agreed with the information regarding Au found in JCPDS 04-0784. The growth of Au in this manufacturing process has a strong preferential (111) orientation, as has been reported in previous articles [22,23]. The intensity ratios of the $\mathrm{Au}(111) / \mathrm{Au}(200)$ and $\mathrm{Au}(111) / \mathrm{Au}(220)$ peaks amounted to 2.82 and 4.64 for $\mathrm{Au} \mathrm{DNFs} / \mathrm{Si}$, 2.42 and 4.12 for $\mathrm{Au}$ DNFs/TiN/Si. The XRD results of Au DNFs agree with the SAED results in Figures $3 c$ and 4c. TiN(111), TiN(200), TiN(220), and TiN(311) were shown in both TiN/Si and $\mathrm{Au}$ DNFs/TiN/Si, which corresponded to the TiN information in JCPDS38-1420. The preferential orientation of TiN was also (111). The intensity ratios of the TiN(111)/TiN(200) and TiN(111)/TiN(220) peaks amounted to 1.30 and 3.20 for TiN/Si, 1.06 and 2.43 for Au DNFs/TiN/Si.

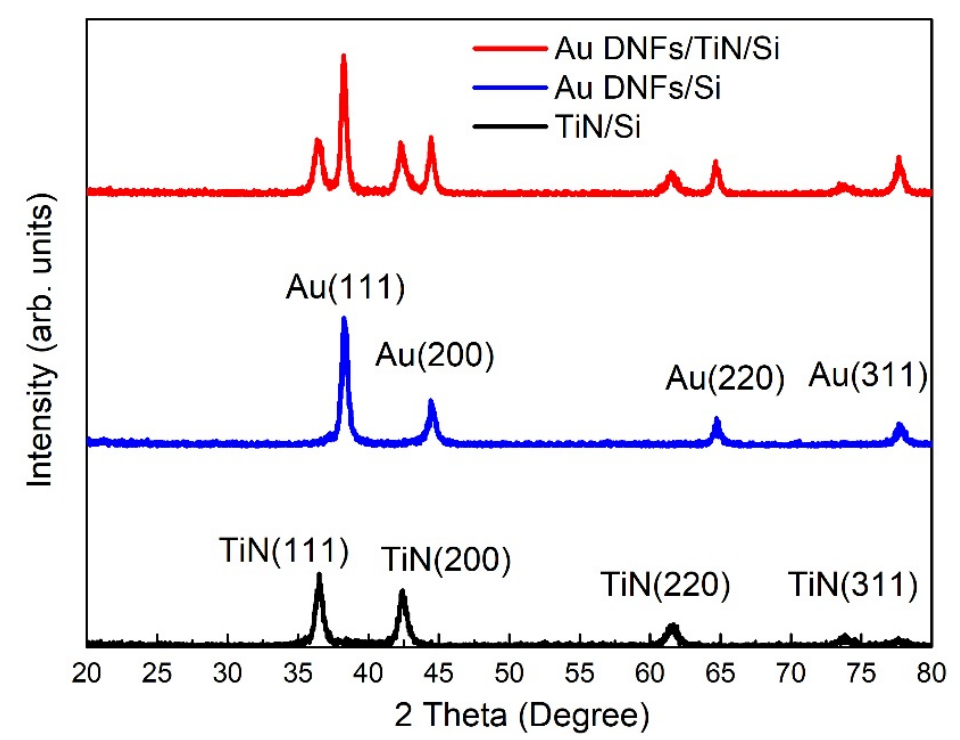

Figure 7. X-ray diffraction (XRD) patterns of the TiN/Si, Au DNFs/Si, and Au DNFs/TiN/Si.

\subsection{Reflectance}

Figure 8 shows that a $\mathrm{Si}$ wafer had an average reflectance of approximately $40 \%$. The $\mathrm{Au}$ $\mathrm{DNFs} / \mathrm{Si}$ or $\mathrm{Au} \mathrm{DNF} / \mathrm{TiN} / \mathrm{Si}$ composites exhibited multiple scattering of incident light between the DNFs, which enhanced light trapping [24]. Therefore, Au DNFs/Si or Au DNFs/TiN/Si exhibited antireflection characteristics with an average reflectance of approximately $10 \%$; in particular, the reflectance in the low wavelength region $(\lambda<500 \mathrm{~nm})$ decreased considerably. Au DNFs with random branches had different sizes, shapes, and gap sizes and thus had various LSPR bands. Broadband LSPR causes broadband absorbance and low reflectance. A similar broadband behavior for the UV-visible spectrum has also been reported for Si-supported Au nanostructures [19].

The reflectance spectrum of Au DNFs/TiN/Si followed that of Au DNFs / Si. That indicates the Au nanostructures grown on the TiN layer dominate the reflectance process. The difference between $\mathrm{Au} \mathrm{DNFs} / \mathrm{TiN} / \mathrm{Si}$ and Au DNFs/Si may be attributed to the synergetic effect of LSPR between the gold nanostructures and TiN film. Although the thickness and density of Au DNFs on substrates were both smaller for $\mathrm{Au} \mathrm{DNF} / \mathrm{TiN} / \mathrm{Si}$ than for Au DNFs/Si, the average reflectance did not vary much due to the addition of TiN, which had resonant plasmon characteristics in the visible spectrum $[9,10]$. 


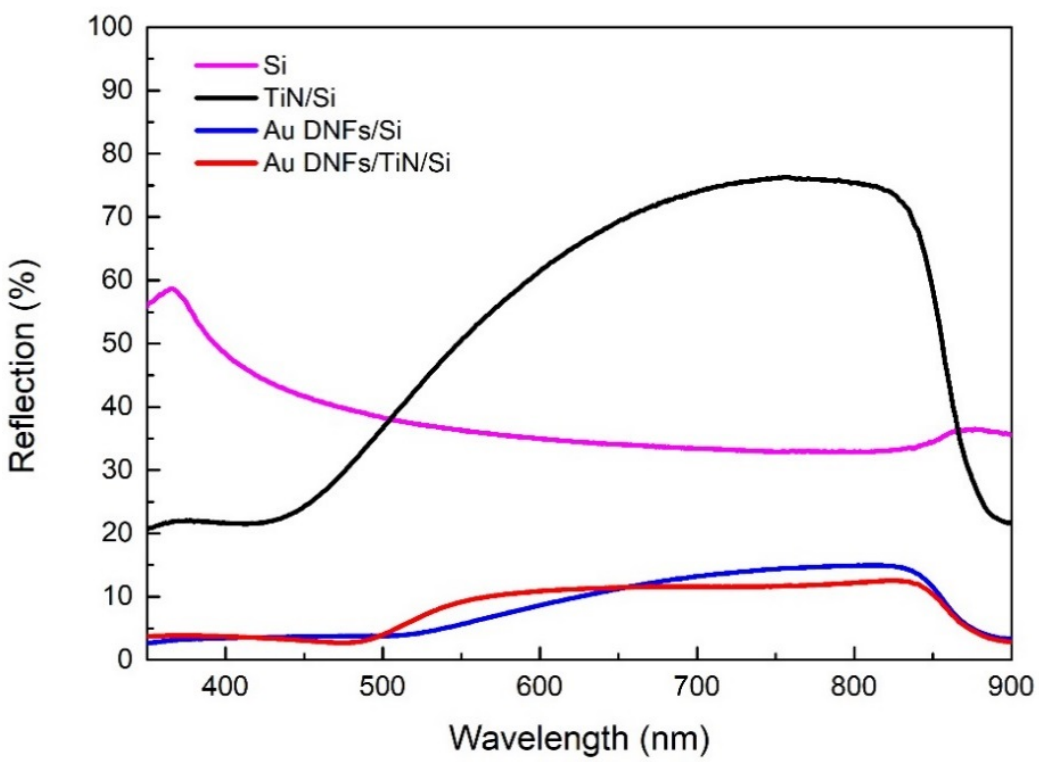

Figure 8. Reflectance spectra of different samples.

\subsection{Photodegradation}

Figure 9 presents photodegradation of 4-nitrophenol. Two samples, Au DNFs/Si, and Au $\mathrm{DNFs} / \mathrm{TiN} / \mathrm{Si}$, were tested in the presence of illumination or in dark environments. Agreeing with previous reports [25-27], results indicated 4-nitrophenol broke down notably in appearance, and concentrations of 4-nitrophenol decreased with time. In $180 \mathrm{~min}$, for the $\mathrm{Au} \mathrm{DNFs/Si}$, and $\mathrm{Au} \mathrm{DNFs} / \mathrm{TiN} / \mathrm{Si}$, the concentrations of 4-nitrophenol were $16.25 \pm 2.83 \%$ and $9.33 \pm 1.41 \%$, respectively, in the presence of illumination, and $26.82 \pm 3.54 \%$ and $24.16 \pm 1.41 \%$, respectively, in the dark. The concentrations in illumination were smaller than dark environments, and therefore illumination showed more photodegradation of 4-nitrophenol than dark. As for the effect of substrate, $\mathrm{Au}$ DNFs/TiN/Si had more photodegradation than Au DNFs/Si.

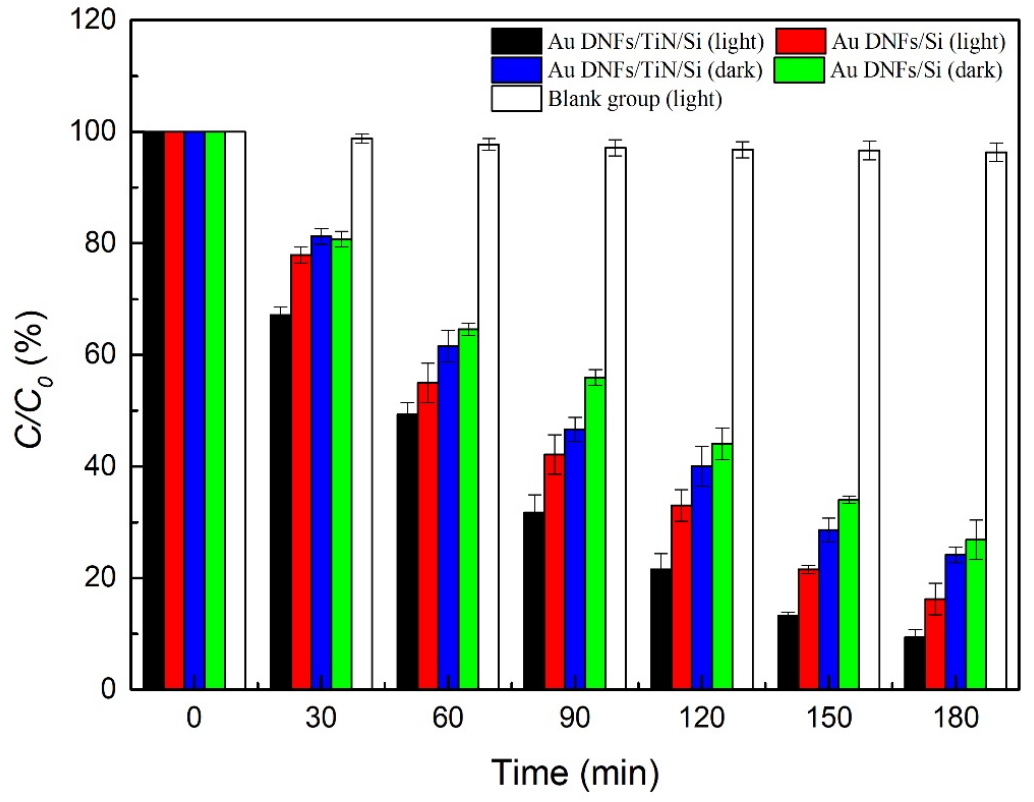

Figure 9. Photodegradation of 4-nitrophenol in $180 \mathrm{~min}$. 
Figure 10 is the curve fitting by the first-order reaction and Table 2 summarizes the reaction rate constant in the photodegradation reaction described by an equation

$$
C / C_{0}=e^{-k t}
$$

where $C / C_{0}$ is the concentration fraction, $t$ is the reaction time, and $k$ is the reaction rate constant. The toptimal degradation happened on the Au DNFs/TiN/Si composite in the presence of illumination.

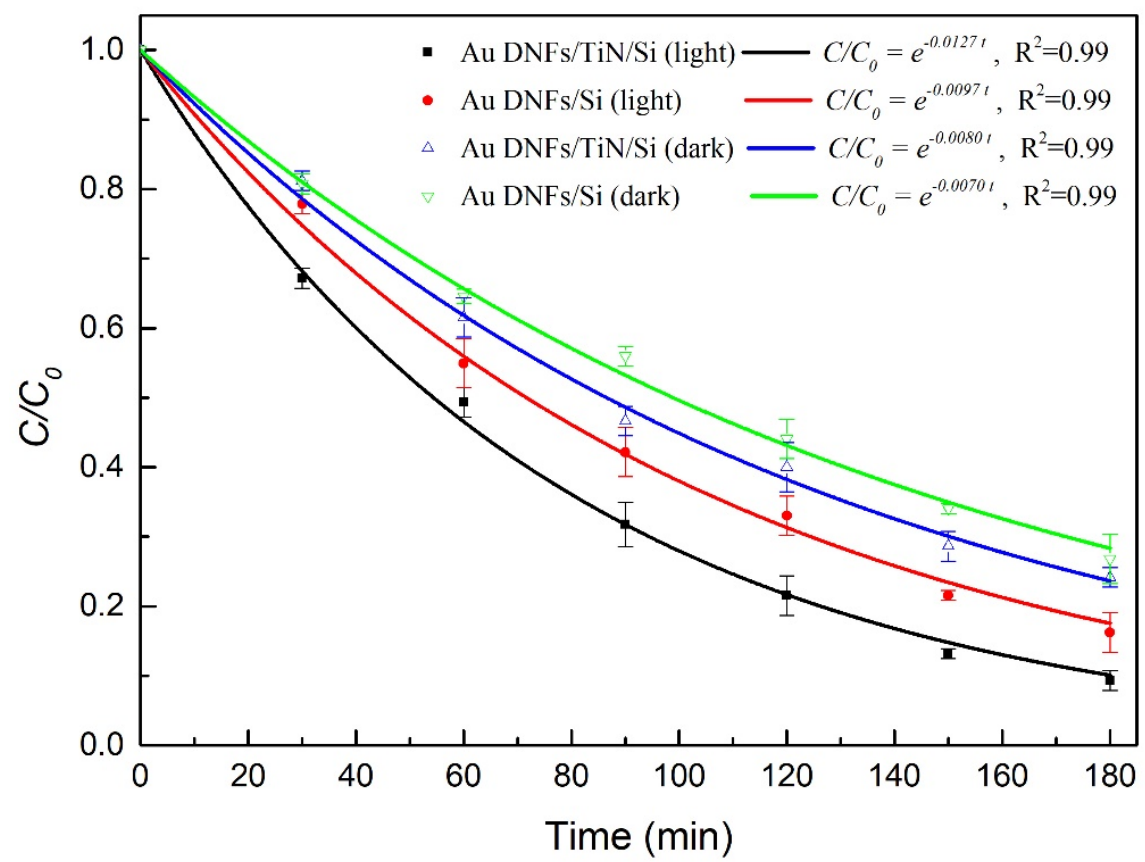

Figure 10. Curve fitting of 4-nitrophenol photodegradation in $180 \mathrm{~min}$.

Table 2. The reaction rate constant in the photodegradation reaction.

\begin{tabular}{cc}
\hline Sample & Reaction Rate Constant $\left(\times \mathbf{1 0}^{-\mathbf{3}} \mathbf{1} \mathbf{1} \mathbf{m i n}\right)$ \\
\hline Au DNFs/Si (dark) & 7.0 \\
Au DNFs/TiN/Si (dark) & 8.0 \\
Au DNFs/Si (light) & 9.7 \\
Au DNFs/TiN/Si (light) & 12.7 \\
\hline
\end{tabular}

Figure 11 is the chronoamperometry test of $500 \mathrm{~mL} 2.5 \times 10^{-5} \mathrm{M}$ 4-nitrophenol solution with $0.5 \mathrm{M} \mathrm{NaOH}$. Results indicated that photocatalytical reaction of 4-nitrophenol was enhanced under illumination. Regardless of the samples, the current density under illumination was higher than that in the dark. In addition, Au DNFs/TiN/Si had a higher current density than Au DNFs/Si, corresponding to the photodegradation result in Figure 9.

The visible-light enhanced degradation could be attributed to the synergetic effect between $\mathrm{Au}$ DNFs and the TiN layer. Figure 12 shows the schematic diagram of visible-light induced degradation on Au-TiN composites. The Au DNFs/Si and Au DNFs/TiN/Si composites can exhibit multiple scattering of incident light between the DNFs and enrich light trapping [24]. Besides, the enhanced efficiency of 4-nitrophenol degradation for $\mathrm{Au} \mathrm{DNFs} / \mathrm{Si}$ and $\mathrm{Au} \mathrm{DNFs} / \mathrm{TiN} / \mathrm{Si}$ under illumination is attributed to the broadband LSPR generated on Au nanoforests. The Au nanoforests provide multiple sizes and various directions to harvest the broadband illumination. A previous publication reported the visible light enhanced methanol oxidation by silicon-based gold nanodendrites [19]. It is also widely accepted that gold nanostructures can serve as the photocatalyst due to the LSPR generated under 
illumination $[19,27-29]$. The enhanced performance of gold nanostructures for LSPR applications are reported $[30,31]$.

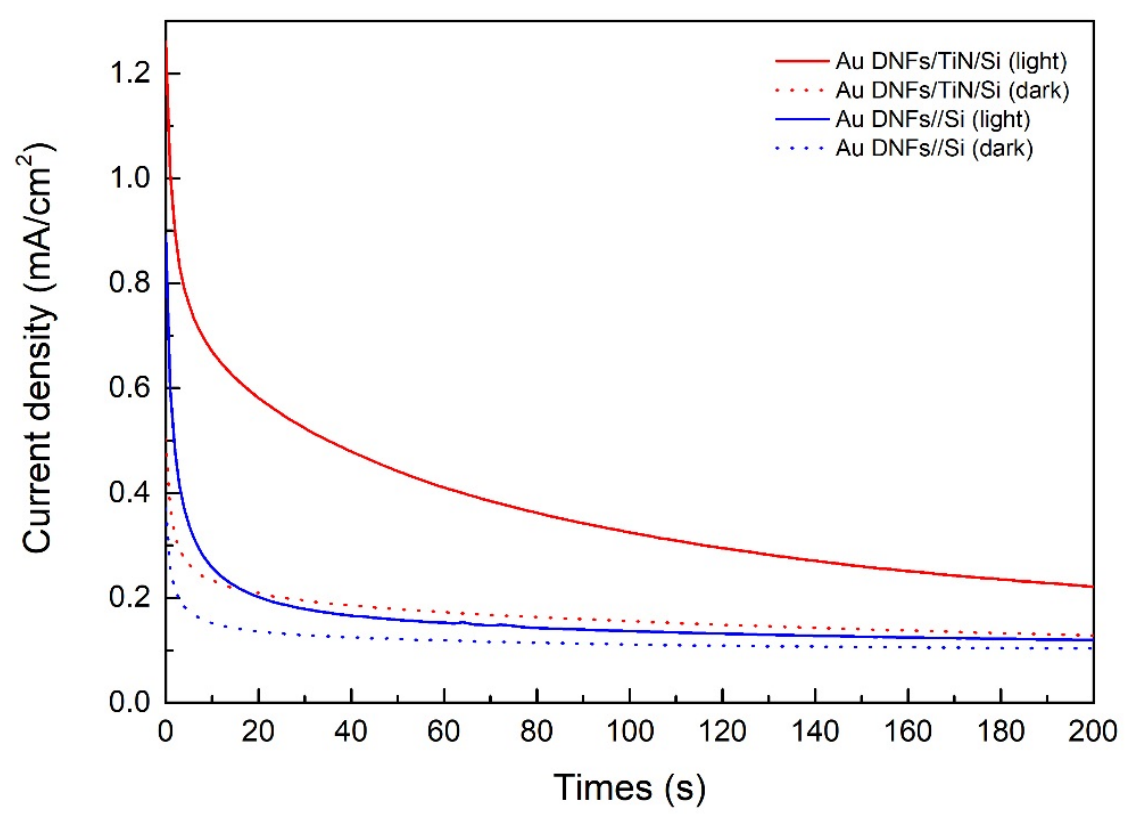

Figure 11. Chronoamperometry test of 4-nitrophenol solution.

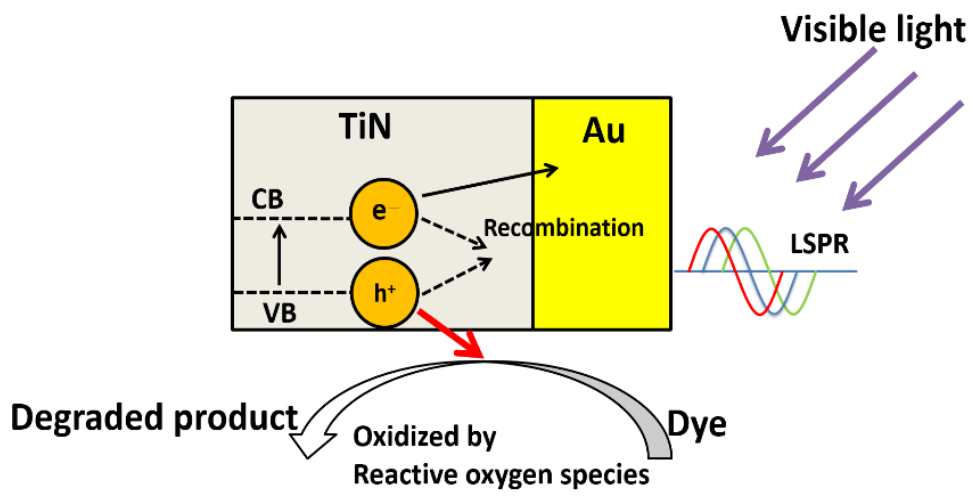

Figure 12. The schematic diagram of visible-light induced degradation on Au-TiN composites.

The photodegradation results (Table 2) show that the efficiency of photodegradation is enhanced on $\mathrm{Au} \mathrm{DNFs} / \mathrm{TiN} / \mathrm{Si}$ comparing to Au DNFs/Si. We attributed the results to the plasmonic effect of TiN supported Au DNFs and band modification of TiN by Au nanostructures. The combination of $\mathrm{Au}$ DNFs and TiN can reduce the band gap of TiN to promote electrons from the valence band of TiN into the conduction band [32]. As generally agreed in the metal-semiconductor interface, the gold nanostructures can serve as the sink for electrons and increase the lifetime of the photogenerated electrons and holes under illumination. The longer lifetimes of the photoexcited electron-hole pairs favor the formation of reactive oxygen species, such as superoxides $\left(\mathrm{O}_{2}{ }^{-}\right)$, hydroxyl radicals (HO-), and etc. [33]. The highly reactive oxygen species can react with and destroy organic dyes by a fast ring-opening process and a complete mineralization of chromophores [32,34].

\section{Conclusions}

In this study, Au DNFs was firstly deposited on the TiN for photocatalysis. Hierarchical Au DNFs with multiple branch sizes were decorated on the surface of TiN/Si by FAGRR for the photodegradation 
of organic dyes under visible-light illumination. In photodegradation tests, $\mathrm{Au} \mathrm{DNFs} / \mathrm{TiN} / \mathrm{Si}$ successfully degraded approximately $90.66 \pm 1.41 \%$ 4-nitrophenol using visible light within $180 \mathrm{~min}$. The enhancement of photodegradation could be attributed to the coupling effect between the LSPR and band modification of TiN. The Au DNFs/TiN/Si composites proposed in this paper show a potential to be used in visible-light induced photodegradation. Additionally, the facile electroless deposition process introduced in this paper provides a new approach in preparing metal-TiN composites.

Author Contributions: M.-H.S., C.-T.L. and Y.-S.L. conceived and designed the experiments; J.-J.Z. performed the experiments; Y.-S.L. wrote the paper.

Funding: This research was funded by Ministry of Science and Technology, Taiwan (grant numbers: MOST 105-2221-E-492-003-MY2 \& 106-2622-E-239-001-CC3).

Acknowledgments: The authors are grateful for the help of sample preparation and measurements by Bo-Huei Liao, Ping-Hsi Chen, Chih-Jung Lu, and Nancy Chu.

Conflicts of Interest: The authors declare no conflict of interest. The founding sponsors had no role in the design of the study; in the collection, analyses, or interpretation of data; in the writing of the manuscript, and in the decision to publish the results.

\section{References}

1. Turki, A.; Guillard, C.; Dappozze, F.; Berhault, G.; Ksibi, Z.; Kochkar, H. Design of $\mathrm{TiO}_{2}$ nanomaterials for the photodegradation of formic acid-Adsorption isotherms and kinetics study. J. Photochem. Photobiol. A Chem. 2014, 279, 8-16. [CrossRef]

2. Chatterjee, D.; Mahata, A. Visible light induced photodegradation of organic pollutants on dye adsorbed $\mathrm{TiO}_{2}$ surface. J. Photochem. Photobiol. A Chem. 2002, 153, 199-204. [CrossRef]

3. Krejčíková, S.; Matějová, L.; Kočí, K.; Obalová, L.; Matěj, Z.; Čapek, L.; Šolcová, O. Preparation and characterization of Ag-doped crystalline titania for photocatalysis applications. Appl. Catal. B Environ. 2012, 111-112, 119-125. [CrossRef]

4. Thomas, J.; Yoon, M. Facile synthesis of pure $\mathrm{TiO}_{2}(\mathrm{~B})$ nanofibers doped with gold nanoparticles and solar photocatalytic activities. Appl. Catal. B Environ. 2012, 111-112, 502-508. [CrossRef]

5. Fu, P.; Zhang, P.; Li, J. Photocatalytic degradation of low concentration formaldehyde and simultaneous elimination of ozone by-product using palladium modified $\mathrm{TiO}_{2}$ films under $\mathrm{UV}_{254+185 \mathrm{~nm}}$ irradiation. Appl. Catal. B Environ. 2011, 105, 220-228. [CrossRef]

6. Vargas Hernández, J.; Coste, S.; Murillo, A.G.; Romo, F.C.; Kassiba, A. Effects of metal doping (Cu, Ag, Eu) on the electronic and optical behavior of nanostructured $\mathrm{TiO}_{2}$. J. Alloys Compd. 2017, 710, 355-363. [CrossRef]

7. López Ortiz, A.; Zaragoza, M.M.; Gutiérrez, J.S.; Paula, M.M.D.; Collins-Martínez, V. Silver oxidation state effect on the photocatalytic properties of $\mathrm{Ag}$ doped $\mathrm{TiO}_{2}$ for hydrogen production under visible light. Int. J. Hydrogen Energy 2015, 40, 17308-17315. [CrossRef]

8. Wang, H.; Yan, J.; Chang, W.; Zhang, Z. Practical synthesis of aromatic amines by photocatalytic reduction of aromatic nitro compounds on nanoparticles $\mathrm{N}$-doped $\mathrm{TiO}_{2}$. Catal. Commun. 2009, 10, 989-994. [CrossRef]

9. White, N.; Campbell, A.L.; Grant, J.T.; Pachter, R.; Eyink, K.; Jakubiak, R.; Martinez, G.; Ramana, C.V. Surface/interface analysis and optical properties of RF sputter-deposited nanocrystalline titanium nitride thin films. Appl. Surf. Sci. 2014, 292, 74-85. [CrossRef]

10. Zhao, J.; Lin, J.; Wei, H.; Li, X.; Zhang, W.; Zhao, G.; Bu, J.; Chen, Y. Surface enhanced Raman scattering substrates based on titanium nitride nanorods. Opt. Mater. 2015, 47, 219-224. [CrossRef]

11. Zhang, L.A.; Liu, H.N.; Suo, X.X.; Tong, S.; Li, Y.L.; Jiang, Z.T.; Wang, Z. Plasmonic properties of titanium nitride thin films prepared by ion beam assisted deposition. Mater. Lett. 2016, 185, 295-298. [CrossRef]

12. Lorite, I.; Serrano, A.; Schwartzberg, A.; Bueno, J.; Costa-Krämer, J.L. Surface enhanced Raman spectroscopy by titanium nitride non-continuous thin films. Thin Solid Films 2013, 531, 144-146. [CrossRef]

13. Kim, W.M.; Kim, S.H.; Lee, K.S.; Lee, T.S.; Kim, I.H. Titanium nitride thin film as an adhesion layer for surface plasmon resonance sensor chips. Appl. Surf. Sci. 2012, 261, 749-752. [CrossRef]

14. Cesiulis, H.; Ziomek-Moroz, M. Electrocrystallization and electrodeposition of silver on titanium nitride. J. Appl. Electrochem. 2000, 30, 1261-1268. [CrossRef] 
15. Wu, Y.; Chen, W.C.; Fong, H.P.; Wan, C.C.; Wang, Y.Y. Displacement reactions between metal ions and nitride barrier layer/silicon substrate. J. Electrochem. Soc. 2002, 149, G309. [CrossRef]

16. Koo, H.C.; Ahn, E.J.; Kim, J.J. Direct-electroplating of Ag on pretreated TiN surfaces. J. Electrochem. Soc. 2008, 155, D10. [CrossRef]

17. O'Kelly, J.P.; Mongey, K.F.; Gobil, Y.; Torres, J.; Kelly, P.V.; Crean, G.M. Room temperature electroless plating copper seed layer process for damascene interlevel metal structures. Microelectron. Eng. 2000, 50, 473-479. [CrossRef]

18. Sakai, N.; Fujiwara, Y.; Arai, M.; Yu, K.; Tatsuma, T. Electrodeposition of gold nanoparticles on ITO: Control of morphology and plasmon resonance-based absorption and scattering. J. Electroanal. Chem. 2009, 628, 7-15. [CrossRef]

19. Lin, C.T.; Chang, M.N.; Huang, H.J.; Chen, C.H.; Sun, R.J.; Liao, B.H.; Chau, Y.F.C.; Hsiao, C.N.; Shiao, M.H.; Tseng, F.G. Rapid fabrication of three-dimensional gold dendritic nanoforests for visible light-enhanced methanol oxidation. Electrochim. Acta 2016, 192, 15-21. [CrossRef]

20. Liao, B.H.; Chan, S.H.; Lee, C.C.; Kuo, C.C.; Chen, S.H.; Chiang, D. FTO films deposited in transition and oxide modes by magnetron sputtering using tin metal target. Appl. Opt. 2014, 53, A148-A153. [CrossRef] [PubMed]

21. Carraroa, C.; Maboudiana, R.; Magagnin, L. Metallization and nanostructuring of semiconductor surfaces by galvanic displacement processes. Surf. Sci. Rep. 2007, 62, 499-525. [CrossRef]

22. Lahiri, A.; Wen, R.; Kuimalee, S.; Kobayashi, S.; Park, H. One-step growth of needle and dendritic gold nanostructures on silicon for surface enhanced Raman scattering. CrystEngComm 2012, 14, 1241-1246. [CrossRef]

23. Lahiri, A.; Wen, R.; Kuimalee, S.; Chowdhury, A.; Kobayashi, S.; Zhang, L.; Wang, P.; Fang, Y. Photo-assisted control of gold and silver nanostructures on silicon and its SERRS effect. J. Phys. D Appl. Phys. 2013, 46, 275303. [CrossRef]

24. Jung, J.Y.; Guo, Z.; Jee, S.W.; Um, H.D.; Park, K.T.; Lee, J.H. A strong antireflective solar cell prepared by tapering silicon nanowires. Opt. Mater. Express 2010, 18, A286-A292. [CrossRef] [PubMed]

25. Huang, J.; Vongehr, S.; Tang, S.; Lu, H.; Shen, J.; Meng, X. Ag dendrite-based Au/Ag bimetallic nanostructures with strongly enhanced catalytic activity. Langmuir 2009, 25, 11890-11896. [CrossRef] [PubMed]

26. Ramakrishna, M.; Babu, D.R.; Gengan, R.M.; Chandra, S.; Rao, G.N. Green synthesis of gold nanoparticles using marine algae and evaluation of their catalytic activity. J. Nanostruct. Chem. 2016, 6, 1-13. [CrossRef]

27. Gu, Y.; Jiao, Y.; Zhou, X.; Wu, A.; Buhe, B.; Fu, H. Strongly coupled Ag/ $\mathrm{TiO}_{2}$ heterojunctions for effective and stable photothermal catalytic reduction of 4-nitrophenol. Nano Res. 2018, 11, 126-141. [CrossRef]

28. Hou, W.; Cronin, S.B. A review of surface plasmon resonance-enhanced photocatalysis. Adv. Funct. Mater. 2013, 23, 1612-1619. [CrossRef]

29. Chau, Y.F.C.; Lee, C.; Huang, H.J.; Lin, C.T.; Chiang, H.P.; Mahadi, A.H.; Voo, N.Y.; Lim, C.M. Plasmonic effects arising from a grooved surface of a gold nanorod. J. Phys. D Appl. Phys. 2017, 50, 125302. [CrossRef]

30. Nishi, H.; Tatsuma, T. Mechanistic analysis of plasmon-induced charge separation by the use of chemically synthesized gold nanorods. J. Phys. Chem. C 2018, 122, 2330-2335. [CrossRef]

31. Bonyár, A.; Csarnovics, I.; Veres, M.; Himics, L.; Csik, A.; Kámán, J.; Balázs, L.; Kökényesi, S. Investigation of the performance of thermally generated gold nanoislands for LSPR and SERS applications. Sens. Actuators B Chem. 2018, 255, 433-439. [CrossRef]

32. Ayati, A.; Tanhaei, B.; Bamoharram, F.F.; Ahmadpour, A.; Maydannik, P.; Sillanpää, M. Photocatalytic degradation of nitrobenzene by gold nanoparticles decorated polyoxometalate immobilized $\mathrm{TiO}_{2}$ nanotubes. Sep. Purif. Technol. 2016, 171, 62-68. [CrossRef]

33. Iliev, V.; Tomova, D.; Rakovsky, S. Nanosized N-doped $\mathrm{TiO}_{2}$ and gold modified semiconductors-Photocatalysts for combined UV-visible light destruction of oxalic acid in aqueous solution. Desalination 2010, 260, 101-106. [CrossRef]

34. Dai, K.; Chen, H.; Peng, T.; Ke, D.; Yi, H. Photocatalytic degradation of methyl orange in aqueous suspension of mesoporous titania nanoparticles. Chemosphere 2007, 69, 1361-1367. [CrossRef] [PubMed]

(C) 2018 by the authors. Licensee MDPI, Basel, Switzerland. This article is an open access article distributed under the terms and conditions of the Creative Commons Attribution (CC BY) license (http:/ / creativecommons.org/licenses/by/4.0/). 